\title{
PAPER
}

Cite this: DOI: $10.1039 / \times 0 \times x 00000 x$

\section{Studies on the Synthesis, Stability and Conformation of 2-Sulfonyl-Oxetane Fragments}

\author{
K. F. Morgan, ${ }^{a}$ I. A. Hollingsworth ${ }^{b}$ and J. A. Bull ${ }^{a *}$
}

Received 00th January 2012, Accepted 00th January 2012

DOI: $10.1039 / x 0 x \times 00000 x$

www.rsc.org/

\begin{abstract}
2-(Arylsulfonyl)oxetanes have been prepared as new structural motifs of interest for medicinal chemistry. These are designed to fit within fragment space and be suitable for screening in fragment based drug discovery, as well as being suitable for further elaboration or incorporation into drug-like compounds. The oxetane ring is constructed through an efficient $\mathrm{C}-\mathrm{C}$ bond forming cyclisation which allows the incorporation of a wide range of aryl-sulfonyl groups. Furthermore, biaryl-containing compounds can be accessed through Suzuki-Miyaura coupling from halogenated derivatives. With a number of oxetane containing fragment compounds available, their $\mathrm{pH}$ stability was assessed, indicating good half-life values for mono-substituted aryl sulfonyl oxetanes across the $\mathrm{pH}$ range (1 to 10). Solubility and metabolic stability data is also reported. Finally, the conformation of the fragments is assessed computationally, providing an indication of possible binding orientations.
\end{abstract}

\section{Introduction}

Recent years have seen significant interest in the preparation of new chemical motifs for medicinal chemistry. ${ }^{1}$ New motifs, including scaffolds and isosteres, can access new areas of chemical space and confer improved physicochemical properties, as well as intellectual property advantages when incorporated into target molecules. ${ }^{2} \mathrm{We}$ are interested in new chemical motifs for incorporation into drug-like compounds, which themselves also provide interesting fragments for fragment based drug discovery (FBDD), to be screened in their own right.

FBDD has become a well-established and important approach to the development of new drugs and lead compounds. ${ }^{3}$ An important advantage of fragment screening is the improved coverage of available chemical space offered by screening smaller molecules. ${ }^{4,5}$ The small size of fragments means that hits are likely to provide desirable starting points for a medicinal chemistry programme, to allow increases in MW and lipophilicity during optimisation of compound properties. ${ }^{6,7}$ To maximise coverage of chemical space, library design will consider many parameters. Within these, the Astex guidelines for fragments are often adhered to (Rule-of-3: MW <300, $\operatorname{cog} \mathrm{P}$ $\leq 3$, number of $\mathrm{H}$-bond donors/acceptors $\leq 3),{ }^{8}$ though increased numbers of $\mathrm{H}$-bond acceptors can aid solubility and provide additional binding elements. ${ }^{9}$ Recent literature has called for an increase in the proportion of $\mathrm{sp}^{3}$ rich fragments and their reduction in planarity. ${ }^{10}$ This is because of observations that more $\mathrm{sp}^{3}$-rich molecules and aliphatic heterocycles can offer improved levels of success through development, relative to highly aromatic compounds. ${ }^{11,12}$ In addition, more $\mathrm{sp}^{3}$ rich fragments may offer the potential for an improved hit rate in challenging biological targets such as protein-protein interactions (PPI) ${ }^{13,4}$ Although there remains debate over the advantages of " 3 -D fragments", there is significant interest to develop synthetic methods towards novel small non-planar fragments that access new chemical space. ${ }^{2,4,7}$

In this context, we considered that novel substituted oxetanes could provide interesting chemical motifs and fragments. ${ }^{14,15}$ The oxetane motif is found in a variety of natural products and biologically active compounds (Figure 1A). ${ }^{16}$ However, the recent increased interest in applying oxetanes in medicinal chemistry follows studies by Carreira and co-workers, in which the incorporation of 3,3-disubstituted oxetanes in place of gem-dimethyl groups was studied (Figure 1B). ${ }^{17}$

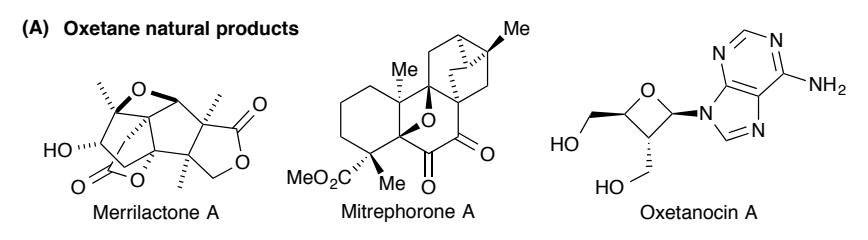

(B) Oxetane as a replacement group (refs 17-20)

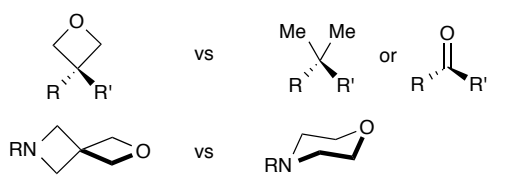

Figure 1. The oxetane motif in natural products and as bioisosteres in medicinal chemistry. 
It was demonstrated that this use of oxetanes as replacement groups could impart improved physicochemical properties to drug-like compounds, without a significant increase in molecular weight. ${ }^{18 a}$ Carreira extended this approach to use oxetanes as replacements for carbonyl groups, ${ }^{18,1 \mathrm{~d}}$ with the oxetane providing comparable $\mathrm{H}$-bonding properties, and recently oxetanes have been introduced in peptide mimics. ${ }^{19}$ Similarly, Carreira has subsequently developed several novel spirocyclic systems containing oxetanes, e.g. as replacements for a morpholine group (Figure 1B). ${ }^{20}$ Following these advances, the appearance of oxetanes in medicinal chemistry has seen a notable increase, with particular aims of improving solubility or metabolic stability of drug-like compounds. ${ }^{21,22,23}$

We recently communicated our initial studies into the synthesis of a series of novel 2-sulfonyl oxetanes 1a-d, designed to possess attractive characteristics as fragments for fragment based drug discovery (Figure 2). ${ }^{14}$

\begin{tabular}{|c|c|c|c|c|c|}
\hline & & $\mathrm{Ar}$ & MW & $\operatorname{cLog} \mathrm{P}( \pm 0.4)$ & $\mathrm{HBD} / \mathrm{HBA}$ \\
\hline & $\begin{array}{l}1 \mathrm{a} \\
1 \mathrm{~b} \\
1 \mathrm{c} \\
\mathbf{1 d}\end{array}$ & $\begin{array}{l}\mathrm{C}_{6} \mathrm{H}_{5} \\
4-\mathrm{MeC}_{6} \mathrm{H}_{4} \\
4-\mathrm{ClC}_{6} \mathrm{H}_{4} \\
\text { 2-pyr }\end{array}$ & $\begin{array}{l}198 \\
212 \\
232 \\
199\end{array}$ & $\begin{array}{r}-0.20 \\
0.26 \\
0.35 \\
-1.28\end{array}$ & $\begin{array}{l}0 / 3 \\
0 / 3 \\
0 / 3 \\
0 / 4\end{array}$ \\
\hline
\end{tabular}

Figure 2. Previously reported 2-aryl sulfonyl oxetanes as fragments and their molecular properties (Reference 14$)^{\ddagger}$

The incorporation of the small and polar oxetane heterocycles and the sulfonyl group provides desirable molecular weight and lipophilicity properties for fragments, and affords potential sites for binding interactions. Furthermore, we intended the functionality to facilitate further derivatisation for fragment growth or incorporation into larger compounds. Here we report our full studies into the synthesis of a wide array of 2-sulfonyl oxetanes, as well as derivatisation of the initial fragments maintaining the intact oxetane ring. We also report studies relevant to their potential and properties as fragments, indicating their stability to a range of $\mathrm{pH}$ conditions as well as indications of metabolic stability, solubility and calculated conformational features.

\section{Results and Discussion}

\section{Synthesis of 2-(arylsulfonyl)oxetane derivatives}

The synthesis of the oxetane motif remains a challenge due to the poor thermodynamics and kinetics of cyclisation to form 4membered rings. The most widely used synthetic approaches to oxetanes involve $\mathrm{C}-\mathrm{O}$ bond formation, often via intramolecular alkylation of a hydroxyl group, by a number of methods. ${ }^{24,25}$ These approaches were not suitable for the proposed sulfonyl oxetane compounds due to rapid elimination from the required $\alpha$-hydroxy sulfonyl intermediates. Studies into displacing the leaving group adjacent to the sulfonyl group with a primary alcohol were similarly unsuccessful. Therefore, a different approach was required to access the proposed 2-sulfonyl oxetanes, for which we examined a $\mathrm{C}-\mathrm{C}$ bond forming cyclisation approach (Scheme 1). ${ }^{14,15,26}$ We envisaged that deprotonation next to the sulfone would provide a more reactive carbanion (vs an oxy-anion) that may facilitate cyclisation to the 4-membered ring.

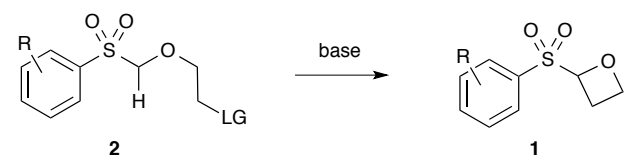

Scheme 1. Carbon-carbon bond forming approach to 2-aryl sulfonyl oxetanes.

To commence the synthesis towards the precursor for cyclisation, of general structure 2, we required chloromethylsulfides 5a-k (Scheme 2). Chloromethyl phenyl sulfide 5a was commercially available and used as supplied. Most other examples were prepared by chlorination of the aryl methyl sulfide with NCS (1.1 equiv), in either $\mathrm{CCl}_{4}{ }^{27}$ or latterly with DCE, which was equally efficient. Filtration through silica, eluting with $\mathrm{CH}_{2} \mathrm{Cl}_{2}$, gave the sulfides in high yield and purity without further purification. For pyridyl substrate 5d, the chloromethyl sulfide was obtained in one step by alkylation of mercaptopyridine 4d with $\mathrm{NaH}$ and chloroiodomethane in DMF. ${ }^{28}$ Chloromethyl sulfides $\mathbf{5}$ were then used to alkylate ethylene glycol. Ethylene glycol was employed as a solvent, which avoided double alkylation and provided S,O-acetals 6ak. Tosylation of the primary alcohol followed by oxidation with excess $m$ CPBA to the corresponding sulfones afforded the cyclisation precursors $\mathbf{2}$ in high yields.

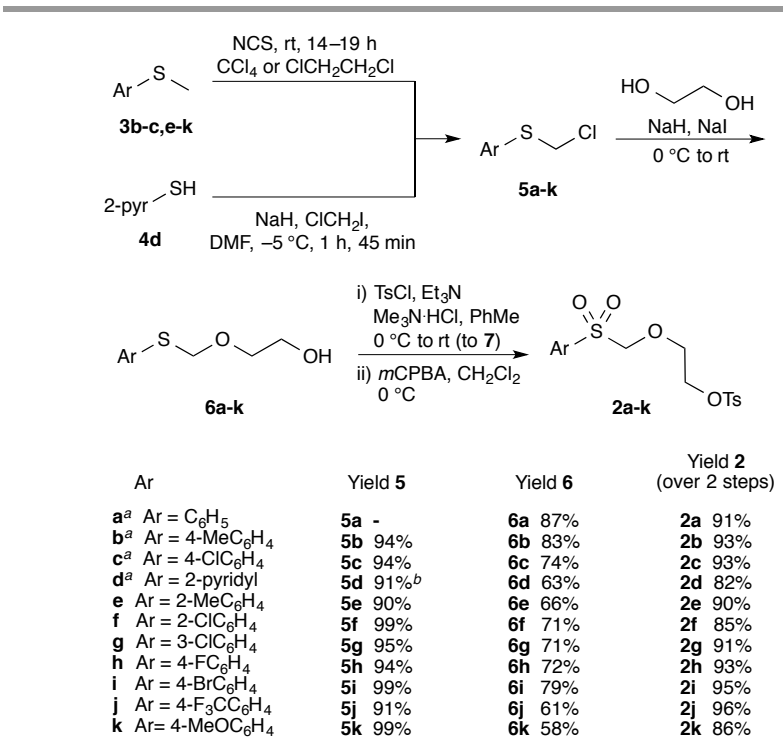

Scheme 2. Synthetic route to the cyclisation precursors; sulfone 2 from the corresponding chloromethyl sulfides. ${ }^{a}$ See reference 14 for compounds a-d. ${ }^{b}$ Isolated as a 9:1 mixture with bis(pyridine-2-ylthio)methane.

Optimisation of the $\mathrm{C}-\mathrm{C}$ bond forming cyclisation was performed on compound $\mathbf{2 b} .^{14}$ Initially sulfone $\mathbf{2 b}$ was deprotonated with a variety of bases; freshly made LiHMDS was optimal. The deprotonation and cyclisation occurred efficiently at $0{ }^{\circ} \mathrm{C}$. The order of addition of reactants was important; when LiHMDS was added to a solution of the sulfone it gave a marked increase in yield when compared to adding sulfone $\mathbf{2 b}$ to a solution of LiHMDS. Decreasing the 
reaction time to $1 \mathrm{~h}$ and the equivalents of base to 1.1 afforded the optimum cyclisation conditions. Under these conditions, a $93 \%$ isolated yield was obtained on a $6 \mathrm{mmol}$ scale, providing $>1 \mathrm{~g}$ of the sulfonyl oxetane fragment $\mathbf{1 b}$ (Scheme 3 ).

These conditions ( 1.1 equiv LiHMDS, $\left.0{ }^{\circ} \mathrm{C}, 1 \mathrm{~h}\right)$ were applied to sulfones $\mathbf{2 a , c - k}$ to afford the resulting 2-sulfonyl oxetanes in yields from $46-95 \%$ (Scheme 3 ). The cyclisation was successful with a variety of aromatic groups of varying size and electronics. A phenyl, para-tolyl, para-chloro phenyl and 2-pyridine ring were all high yielding under the optimised conditions 1a-d. Substitution at the ortho- and meta-positions of the aromatic ring were also successful 1e-g. As well as chloro substituents, both the fluoro and bromo substrates, $\mathbf{1 h}$ and $\mathbf{1 i}$, were obtained in high yields $(83 \%$ and $86 \%)$. The introduction of halogen substituents at all positions provides opportunities for further derivatisation of the sulfonyl oxetane. Both electron withdrawing and electron donating substrates were successful $\mathbf{1 j}$ and $\mathbf{1 k}$. Each of the compounds prepared (Scheme 3) fit well into fragment space in terms of molecular weight (MW) and lipophilicity values $(\mathrm{cLogP})$. Furthermore they present a number of H-bond acceptors, generally $<4$ as is appropriate for additional binding elements and further points for derivatisation. ${ }^{9}$

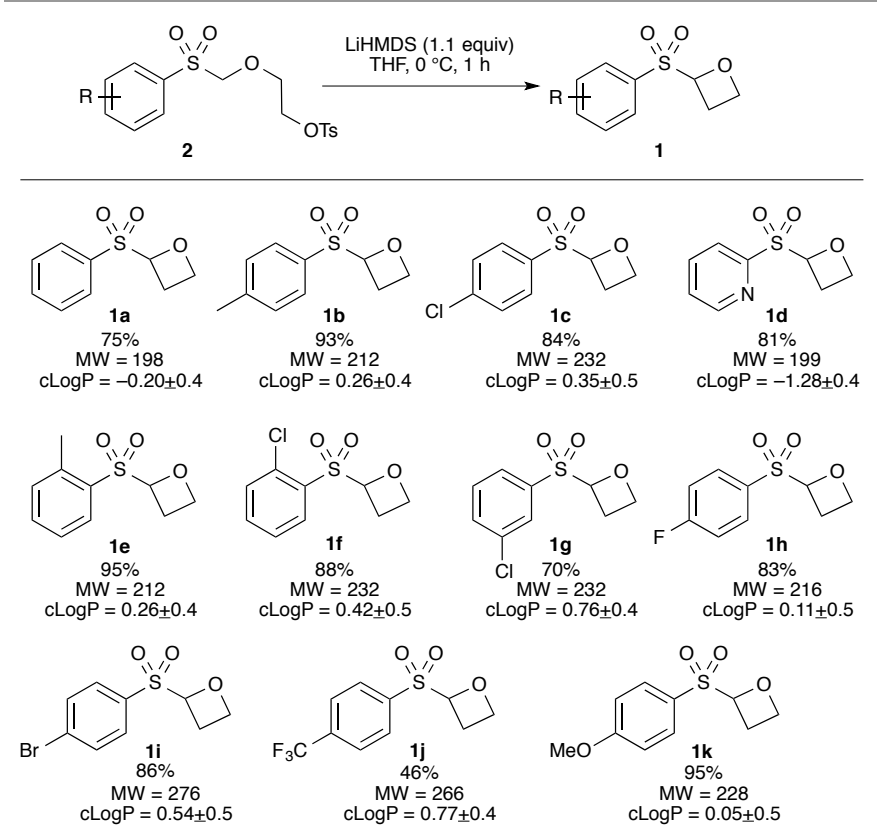

Scheme 3. Library of 2-sulfonyl oxetane fragments synthesised via an intramolecular $\mathrm{C}-\mathrm{C}$ bond forming cyclisation.

As new motifs we were interested in methods for the incorporation of the 2-sulfonyl oxetanes into larger compounds, and as fragments we desired methods for their growth into leadlike and drug-like compounds were they to be a hit. With this in mind, an important aspect of the design of these fragments was to allow their further derivatisation. Initially, functionalisation on the intact oxetane ring via lithiation followed by electrophilic trapping was investigated, to generate 2,2disubstituted oxetanes (Scheme 4). This deprotonation and electrophilic trapping was achieved under two sets of conditions appropriate for different electrophiles, both in excellent yields. When LiHMDS was employed the electrophile was added immediately. To maintain stability of the lithiated intermediate, the reagents were added at $-78{ }^{\circ} \mathrm{C}$ then warmed to $0{ }^{\circ} \mathrm{C}$ for an in situ quench. However when $n \mathrm{BuLi}$ was used, to achieve full deprotonation the electrophile was added after a short deprotonation time and the reactions were maintained at $-78{ }^{\circ} \mathrm{C}$. For compounds 8-12, purification on silica afforded reduced yields, and compounds required purification on basic alumina. ${ }^{29}$

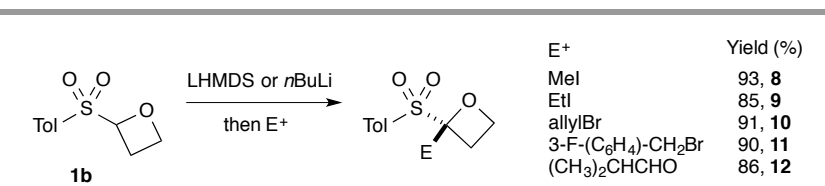

Scheme 4. Functionalisation of 2-aryl sulfonyl oxetanes directly on the intact oxetane ring via lithiation. ${ }^{14}$

We were interested in the viability of the 2-sulfonyl oxetane units as cross-coupling partners, to access functionalised biaryl systems. This was realised through Suzuki-Miyaura crosscoupling using $\mathrm{Pd}(\mathrm{OAc})_{2}$ with Buchwald's SPhos ligand (Scheme 5). ${ }^{30}$

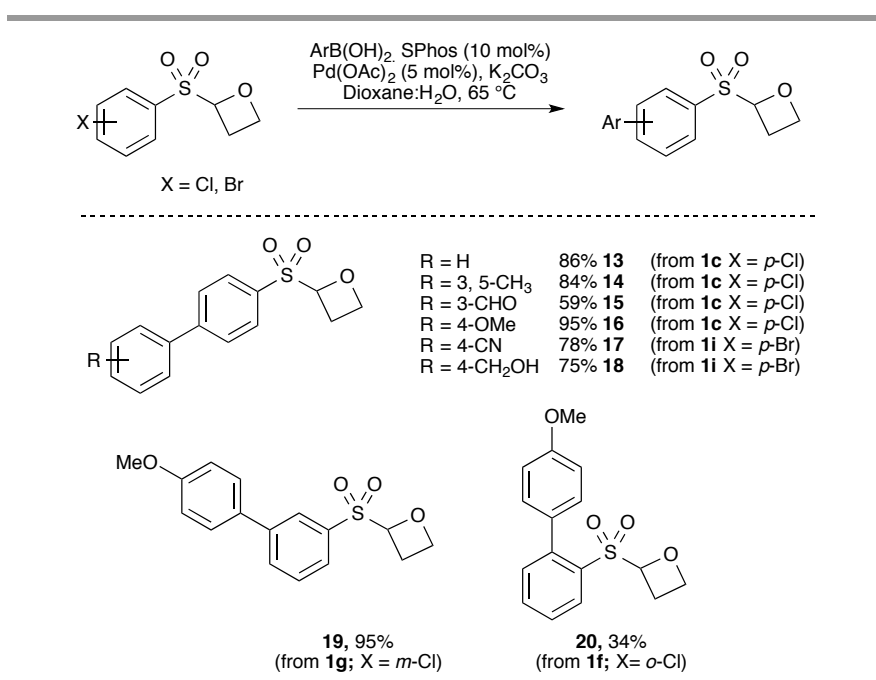

Scheme 5. Catalytic cross-coupling of chloro and bromo-substituted aryl sulfonyl oxetanes accessing a variety of biaryl products. See reference 14 for compounds 13-16.

The para-chloro phenyl substrate 1c was successfully coupled with a variety of boronic acids, both electron withdrawing and electron donating to afford biaryls 13-16. ${ }^{31}$ Under these cross-coupling conditions, the halide and boronic acid were heated in water/dioxane at $65{ }^{\circ} \mathrm{C}$ in the presence of $\mathrm{K}_{2} \mathrm{CO}_{3}$; it was interesting to note that no degradation or ring opening of the oxetane was observed. The para-bromo phenyl sulfonyl oxetane 1i was also coupled with 4cyanophenylboronic acid and 4-(hydroxymethyl)-phenylboronic acid in good yields, installing further reactive handles. Pleasingly both meta and ortho chlorides $\mathbf{1 g}$ and $\mathbf{1 f}$ were also successfully cross-coupled with 4-methoxyphenyl-boronic acid 
under the same reaction conditions to afford biaryl compounds 19 and 20, demonstrating how the 2-sulfonyl oxetane fragments could be derivatised in a variety of directions (Scheme 5).

\section{Studies into the Stability of Sulfonyl Oxetanes}

Having accessed a large variety of 2-sulfonyl-oxetanes we were interested to understand more about their desirability as fragments, in particular their stability under acidic conditions. Initial observations on stability to storage showed that all of the oxetane compounds were stable when kept under argon at $-20{ }^{\circ} \mathrm{C}$. Oxetanes 1a-d were stored under argon at $-20{ }^{\circ} \mathrm{C}$ for $>12$ months and samples of fragments $\mathbf{1 b}$ and $\mathbf{1 d}$ were also stored at room temperature without any additional precautions for $>3$ months with no observable degradation. Similarly, biaryl oxetanes $\mathbf{1 3}$ and $\mathbf{1 6}$ were stable when stored under argon at $-20{ }^{\circ} \mathrm{C}$ for at least 8 months and at $\mathrm{rt}$ for at least 3 months. On the other hand, functionalised oxetanes $\mathbf{8}$ and $\mathbf{9}$, which are alkylated directly on the oxetane ring, underwent an unexpected rearrangement when stored at room temperature for more than 24 hours. While stable at $-20{ }^{\circ} \mathrm{C}$ for $>2$ months without degradation, 8 and 9 underwent rearrangement to quantitatively afford the corresponding $\beta$-sulfonyl ketones 21 and 22 at higher temperatures. The proposed mechanism is shown in scheme 6 . With the increased steric demands of the $\alpha$-alkylated derivatives we hypothesise that the sulfonyl group was lost to afford a tertiary carbocationic intermediate, possibly stabilised by the adjacent oxygen. Subsequent ring opening by attack of the sulfonyl group would afford the observed product. Consequently, these 2-alkylated 2-sulfonyl oxetanes were excluded from further stability studies and were considered to be less viable as fragments.

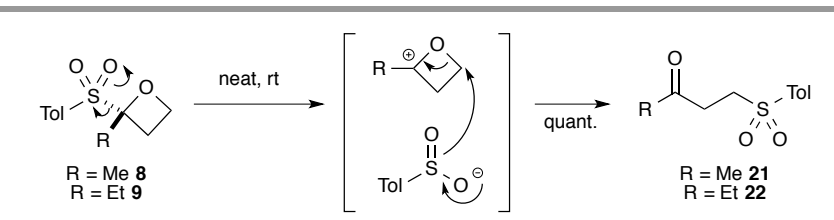

Scheme 6. Proposed decomposition pathway of alkylated oxetanes $\mathbf{8}$ and $\mathbf{9}$.

A selection of mono-substituted sulfonyl oxetanes was subjected to $\mathrm{pH}$ stability studies. The solution stability of compounds 1a-c, $1 \mathrm{~h}$ and $1 \mathrm{k}$ as well as biaryls 13 and 16 were assessed by incubating each compound $(10 \mu \mathrm{M})$ for 15 hours at $70{ }^{\circ} \mathrm{C}$ at $\mathrm{pH} 1,4,6,8$ and 10 in buffers containing $5 \% \mathrm{v} / \mathrm{v} 2$-methoxyethanol. ${ }^{32}$ Analysis was performed at regular intervals by LC-UV-MS. Half-lives were measured at $70{ }^{\circ} \mathrm{C}$ then predicted at $25^{\circ} \mathrm{C}$ calculated using a factor of two for the reduction in rate for every 10 degree reduction in temperature (generally regarded as a worst case scenario). The extrapolated half-lives at $25^{\circ} \mathrm{C}$ are shown in table 1 .
Table 1: Half-lives of selected compounds, showing their stability in acidic and basic conditions.

\begin{tabular}{cccccccc}
\hline \multirow{2}{*}{ Entry } & \multirow{2}{*}{ Compound } & & \multicolumn{5}{c}{ Extrapolated Half Life (days) ${ }^{a}$} \\
\cline { 3 - 8 } & & & $\mathrm{pH}:$ & $\mathrm{pH}:$ & $\mathrm{pH}:$ & $\mathrm{pH}:$ & $\mathrm{pH}:$ \\
& & & 1 & 4 & 6 & 8 & 10 \\
\hline 1 & $\mathrm{Ph}-$ & $\mathbf{1 a}$ & 4.0 & 5.0 & 5.3 & 5.3 & 3.7 \\
2 & $\mathrm{Me}-\mathrm{C}_{6} \mathrm{H}_{4}-$ & $\mathbf{1 b}$ & 7.1 & 10.2 & 9.9 & 9.1 & 9.2 \\
3 & $\mathrm{Cl}-\mathrm{C}_{6} \mathrm{H}_{4}-$ & $\mathbf{1 c}$ & 1.7 & 1.9 & 1.9 & 1.8 & 1.8 \\
4 & $\mathrm{~F}^{-} \mathrm{C}_{6} \mathrm{H}_{4}-$ & $\mathbf{1 h}$ & 2.0 & 2.7 & 2.4 & 2.2 & 3.5 \\
5 & $\mathrm{MeO}-\mathrm{C}_{6} \mathrm{H}_{4}-$ & $\mathbf{1 k}$ & 6.3 & 11.2 & 11.5 & 11.1 & 10.0 \\
6 & $\mathrm{Ph}^{-} \mathrm{C}_{6} \mathrm{H}_{4}-$ & $\mathbf{1 3}$ & 3.9 & 4.7 & 4.7 & 4.6 & 4.6 \\
7 & $\mathrm{MeO}-\mathrm{C}_{6} \mathrm{H}_{4}-\mathrm{C}_{6} \mathrm{H}_{4}-$ & $\mathbf{1 6}$ & 4.6 & 5.7 & 5.7 & 7.1 & 5.3
\end{tabular}

${ }^{a}$ Half life calculated at $25{ }^{\circ} \mathrm{C}$, extrapolated from data measured at $70{ }^{\circ} \mathrm{C}$ using a two-fold reduction in rate for every 10 degree drop in temperature.

For all compounds tested, $\mathbf{1 a - c , h}, \mathbf{k}$ and $\mathbf{1 3}$ and 16, good half-lives were observed across the $\mathrm{pH}$ range, with each compound showing a similar trend. In particular it was notable that there was no significant acid sensitivity; decomposition pathways could be envisaged under acidic conditions through the protonation and ring opening of the oxetane, or through protonation of the sulfonyl group and expulsion of aryl sulfinic acid (similar to the first step of the proposed rearrangement in scheme 6). Despite this possibility, the half-lives at $\mathrm{pH} 1$ were comparable to those under neutral conditions in most cases.

The fate of the compounds under the assay conditions was not conclusive from the MS study. One pathway for decomposition was likely to have been hydrolysis to the parent sulfonic acid, as indicated in Scheme 7 for the chlorinatedsubstrate 1c. This would give rise to a $[\mathrm{M}-\mathrm{H}]^{-}$signal, which was observed during the mass spectrometry studies.

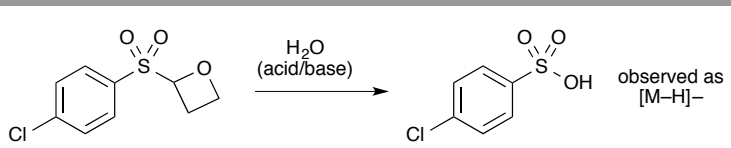

Scheme 7. One possible pathway for decomposition during the stability studies.

Comparing entries 1, 2 and 5 (table 1), it was apparent that the half-lives increased as the aromatic group became more electron rich. This would be consistent with a pathway for decomposition involving a nucleophilic attack at the sulfur center, promoted by the less electron rich/more electron withdrawing substituents on the aryl group. It could also be related to an increased $\alpha$-acidity or leaving group ability of the more electron withdrawing substituents. This trend was further apparent with the biaryl compounds, $\mathbf{1 3}$ and 16. In general the half-lives were comparable to the phenyl derivative, however the more electron rich methoxy-substituted biaryl had a longer half-life under all $\mathrm{pH}$ conditions, compared to biphenyl 13 (entries 6 and 7, table 1).

The $\log \mathrm{D}_{7.4}$ was measured for a small selection of the compounds and indicated the hydrophilic nature of these fragments. As can be seen from table 2, there is not a good correlation with clogP. Additionally, the solubility of compounds 1d and $\mathbf{1 6}$ was assessed in aqueous phosphate buffer at $\mathrm{pH} 7.4$ after 24 hours at $25^{\circ} \mathrm{C}$, however, given the lipophilicity and molecular weight of these fragments, these 
values were disappointingly low, especially for the pyridyl substrate. Further work exploring the possible hydrogen bonding and solvation of these fragments would be required to fully understand these observations.

\begin{tabular}{cccccc}
\hline \multicolumn{6}{l}{ Table 2: Solubility and LogD of sulfonyl oxetanes. } \\
\hline Entry & Compound & $\begin{array}{c}\text { Measured } \\
\operatorname{LogD}\end{array}$ & cLogP & $\begin{array}{c}\text { Solubility } \\
(\mu \mathrm{M})^{a}\end{array}$ \\
\hline 1 & $\mathrm{Pyr}$ & $\mathbf{1 d}$ & -0.3 & -1.3 & 37 \\
2 & $4-\mathrm{MeO}-\mathrm{C}_{6} \mathrm{H}_{4}$ & $\mathbf{1 6}$ & $<-1.1$ & 1.3 & 99 \\
3 & $4-\mathrm{F}-\mathrm{C}_{6} \mathrm{H}_{4}$ & $\mathbf{1 h}$ & $<-1.6$ & 0.11 & -
\end{tabular}

${ }^{a}$ Determined by LCMSMS following incubation of solid compound in $\mathrm{pH}$ 7.4 phosphate buffer at $25^{\circ} \mathrm{C} .{ }^{b}$ Distribution coefficient between 1 -octanol and aqueous phosphate buffer at $\mathrm{pH} 7.4$ at $25^{\circ} \mathrm{C}$ determined by LCMSMS. Other compounds failed to give an acceptable MSMS response under these assay conditions.

Finally for compound 1d, the intrinsic clearance in rat hepatocytes was measured. The value of $2.8 \mu 1 / \mathrm{min} / 1 \mathrm{E} 6$ cells reflects low turnover as would be expected for a fragment of low lipophilicity, and indicates no inherent liability associated with the fragment in terms of metabolism.

\section{Conformational Analysis}

A potentially desirable feature of the 2-sulfonyl oxetanes is the presence of few rotatable bonds, with only rotation around the oxetane-sulfonyl bond possible. In order to understand more about the conformation of these fragments and how they might bind to a potential target the conformational profile of the 2 (phenylsulfonyl)oxetane 1a was investigated by computational methods; a DFT relaxed coordinate scan was performed at B3LYP/6-31G9(d,p) level of theory with default implicit solvation in water $\left(\right.$ scrf $=$ water). ${ }^{33}$ The dihedral angle around the oxetane $\mathrm{C}$-S bond was varied in 10-degree increments between 0 and 360 degrees. The resulting conformational profile is shown in figure 3 .

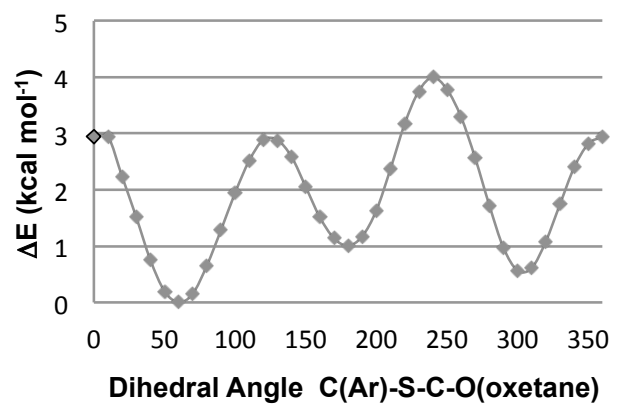

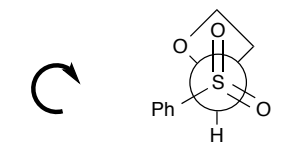

Dihedral angle

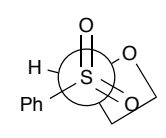

180

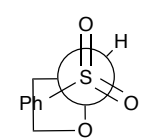

300
Figure 3. Results of the conformational calculations of phenyl sulfonyl oxetane 1a and the three low energy conformations.
There are three preferred conformations corresponding to the staggered conformation of all bonds; with maxima at the eclipsed conformations. Energy minima were observed corresponding to dihedral angles of 60,180 and 300 degrees. Representations of the conformations with the lowest energy are shown in figure 3. The conformation with a 60 degree dihedral angle had the lowest energy presumably due to opposing dipoles as well as minimal steric interactions between the oxetane and phenyl ring. The barriers to rotation as well as the energy difference between the three staggered conformations were relatively low (maximum $4 \mathrm{kcalmol}^{-1}$ ) so the fragment may adopt any of these three conformations.

The same process was performed for the 2-pyridyl substrate 1d. As there were two possible low energy orientations of the pyridyl ring, energies were calculated for each of these, (figure 4).

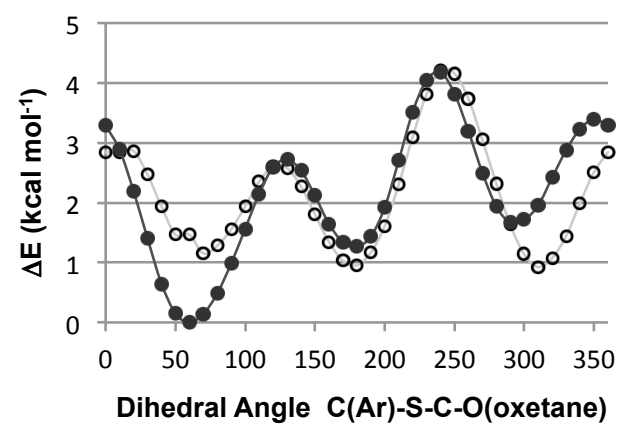

(B) Structure of two low energy conformations of the pyridyl ring

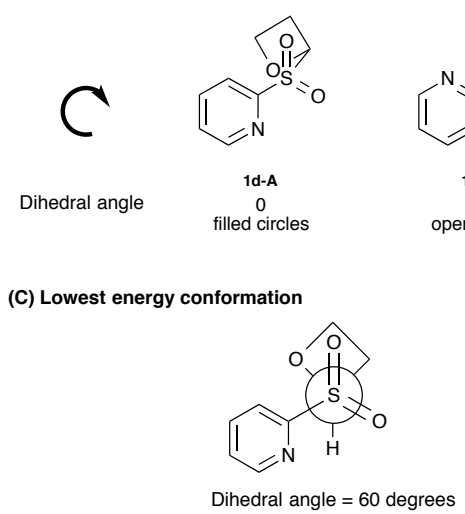

Figure 4. A) Results of the conformational calculations of pyridyl sulfonyl oxetane 1d; B) The two possible orientations of the pyridyl ring; C) Lowest energy conformation for 2-(oxetan-2-ylsulfonyl)pyridine 1d

Both orientations of the pyridyl group 1d-A and 1d-B had three preferred conformations when altering the dihedral angle around the oxetane-C-S bond; similar to those seen for 2-(phenylsulfonyl)oxetane 1a. The minimal energy conformation correlates to the staggered configuration. Conformation 1d-A, with a dihedral angle of 60 degrees was the lowest energy conformation due to opposing dipoles of the pyridine/oxetane, as well as minimal steric hindrance. However, the barrier to rotation was again low. 
The preferred conformation of 2-(2methylbenzenesulfonyl)-oxetane 1e, was also investigated. The calculations were performed for both orientations of the methyl group. The lowest energy conformation had a dihedral angle of 60 degrees, which we postulate results from a favourable intramolecular Van der Waals interaction between a proton on the benzylic $\mathrm{CH}_{3}$ and the oxetane oxygen (figure 5). ${ }^{34}$

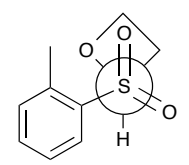

Dihedral angle $=60$ degrees

Figure 5. Lowest energy conformation of 2(2-methylbenzenesulfonyl)oxetane 1e

\section{Conclusions}

In summary we have successfully synthesised a wide array of novel 2-sulfonyl oxetanes that conform well to fragment criteria. These have been further functionalised in a variety of directions via lithiation and Suzuki cross-couplings, as would be appropriate for fragment hits. We have studied their stability and are pleased to show the fragments are stable to basic and more pleasingly acidic conditions. However the derivatised fragments, alkylated on the oxetane ring, undergo a rearrangement at room temperature. Finally calculations have been performed to understand the preferred conformations of a range of these fragments. These understandings enhance the desirability of 2-sulfonyl oxetanes as new motifs for incorporation into medicinal chemistry programs or for use as fragments in FBDD.

\section{Acknowledgements}

For financial support we gratefully acknowledge the EPSRC (Career Acceleration Fellowship to J.A.B., EP/J001538/1, and Impact Acceleration Account, EP/K503733/1), Imperial College London, and AstraZeneca (CASE-type funding). Thank you to Philip MacFaul (AstraZeneca) for performing the stability studies. Thank you to Tom Taylor for early synthetic investigation, and to Prof Alan Armstrong for generous support. We acknowledge the Imperial College High Performance Computing Service (http://www.imperial.ac.uk/ict/services/ teachingandresearchservices/highperformancecomputing), and the EPSRC National Mass Spectrometry Facility, Swansea.

\section{Notes and references}

${ }^{a}$ Department of Chemistry Imperial College London, South Kensington, London SW7 2AZ, UK. Tel: +44 (0)20 7594 5811. E-mail: j.bull@imperial.ac.uk.

${ }^{b}$ AstraZeneca Mereside, Alderley Park, Cheshire, SK10 4TG, UK.

$\dagger$ Electronic Supplementary Information (ESI) available: experimental, characterization data and NMR spectra $\left({ }^{1} \mathrm{H}\right.$ and $\left.{ }^{13} \mathrm{C}\right)$ for all novel compounds. See DOI: 10.1039/b000000x/

+ cLogP values were determined using ACDlabs $\log \mathrm{P}$ calculator http://www.acdlabs.com/resources/freeware/chemsketch/logp.
1 For selected examples see: a) A. F. Stepan, C. Subramanyam, I. V. Efremov, J. K. Dutra, T. J. O’Sullivan, K. J. DiRico, W. S. McDonald, A. Won, P. H. Dorff, C. E. Nolan, S. L. Becker, L. R. Pustilnik, D. R. Riddell, G. W. Kauffman, B. L. Kormos, L. Zhang, Y. Lu, S. H. Capetta, M. E. Green, K. Karki, E. Sibley, K. P. Atchison, A. J. Hallgren, C. E. Oborski, A. E. Robshaw, B. Sneed and C. J. O’Donnell, J. Med. Chem., 2012, 55, 3414-3424. b) D. B. Li, M. Rogers-Evans and E. M. Carreira, Org. Lett., 2011, 13, 6134 6136. c) J. A. Burkhard, C. Guérot, H. Knust and E. M. Carreira, Org. Lett., 2012, 14, 66-69. d) J. A. Burkhard, B. Wagner, H. Fischer, F. Schuler, K. Müller and E. M. Carreira, Angew. Chem. Int. Ed., 2010, 49, 3524-3527. e) J. Wlochal, R. D. M. Davies and J. Burton, Org. Lett., 2014, 16, 4094-4097. f) D. Barnes-Seeman, M. Jain, L. Bell, S. Ferreira, S. Cohen, X. Chen, J. Amin, B. Snodgrass and P. Hatsis, ACS Med. Chem. Lett., 2013, 4, 514-516.

2 F. W. Goldberg, J. G. Kettle, T. Kogej, M. W. D. Perry and N. P. Tomkinson, Drug Discov. Today, 2015, 20, 11-17.

3 a) M. Baker, Nat. Rev. Drug Discovery, 2013, 12, 5-7. b) C. W. Murray, M. L. Verdonk and D. C. Rees, Trends Pharmacol. Sci., 2012, 33, 224-232. c) D. E. Scott, A. G. Coyne, S. A Hudson and C. Abell, Biochemistry, 2012, 51, 4990-5003.

4 R. J. Hall, P. N. Mortenson and C. W. Murray, Prog. Biophys. Mol. Biol., 2014, 116, 82-91.

5 A. R. Leach and M. M. Hann, Curr. Opin. Chem. Biol., 2011, 15, 489-496.

6 M. M. Hann, Med. Chem. Commun., 2011, 2, 349-355.

7 A. Nadin, C. Hattotuwagama and I. Churcher, Angew. Chem. Int. Ed., 2012, 51, 1114-1122.

8 M. Congreve, R. Carr, C. Murray and H. Jhoti, Drug Discov. Today, 2003, 8, 876-877.

9 H. Köster, T. Craan, S. Brass, C. Herhaus, M. Zentgraf, L. Neumann, A. Heine and G. Klebe, J. Med. Chem., 2011, 54, 7784-7796.

10 A. D. Morley, A. Pugliese, K. Birchall, J. Bower, P. Brennan, N. Brown, T. Chapman, M. Drysdale, I. H. Gilbert, S. Hoelder, A. Jordan, S. V. Ley, A. Merritt, D. Miller, M. E. Swarbrick and P. G. Wyatt, Drug Discov. Today, 2013, 18, 1221-1227.

11 F. Lovering, J. Bikker and C. Humblet, J. Med. Chem., 2009, 52, 6752-6756.

12 a) T. J. Ritchie, S. J. F. Macdonald, R. J. Young and S. D. Pickett, Drug Discov. Today, 2011, 16, 164-171. b) T. J. Ritchie, S. J. F. Macdonald, S. Peace, S. D. Pickett and C. N. Luscombe, Med. Chem. Commun., 2013, 4, 673-680.

13 a) J. Bower and A. Pannifer, Curr. Pharm. Des., 2012, 18, 46854696. b) D. E. Scott, M. T. Ehebauer, T. Pukala, M. Marsh, T. L. Blundell, A. R. Venkitaraman, C. Abell and M. Hyvönen, Chem. Bio. Chem., 2013, 14, 332-342.

14 K. F. Morgan, I. A. Hollingsworth and J. A. Bull, Chem. Commun., 2014, 50, 5203-5205.

15 a) O. A. Davis and J. A. Bull, Angew. Chem. Int. Ed., 2014, 53, 14230-14234. b) O. A. Davis and J. A. Bull, Synlett, 2015, DOI: 10.1055/s-0034-1380412.

16 For examples, see: a) H. Shimada, S. Hasegawa, T. Harada, T. Tomisawa, A. Fujii and T. Takita, J. Antibiot., 1986, 39, 1623-1625. 
b) M. C. Wani, H. L. Taylor, M. E. Wall, P. Coggon and A. T. McPhall, J. Am. Chem. Soc., 1971, 93, 2325-2327. c) C. Li, D. Lee, T. N. Graf, S. S. Phifer, Y. Nakanishi, J. P. Burgess, S. Riswan, F. M. Setyowati, A. M. Saribi, D. D. Soejarto, N. R. Farnsworth, J. O. F. Iii, D. J. Kroll, A. D. Kinghorn, M. C. Wani and N. H. Oberlies, Org. Lett., 2005, 7, 5709-5712.

17 G. Wuitschik, M. Rogers-Evans, K. Müller, H. Fischer, B. Wagner, F. Schuler, L. Polonchuk and E. M. Carreira, Angew. Chem. Int. Ed., 2006, 45, 7736-7739.

18 a) G. Wuitschik, E. M. Carreira, B. Wagner, H. Fischer, I. Parrilla, F. Schuler, M. Rogers-Evans and K. Müller, J. Med. Chem., 2010, 53, 3227-3246. b) J. A. Burkhard, G. Wuitschik, J.-M. Plancher, M. Rogers-Evans and E. M. Carreira, Org. Lett., 2013, 15, 4312-4315.

19 a) N. H. Powell, J. G. Clarkson, R. Notman, P. Raubo, N. G. Martin and M. Shipman, Chem. Commun., 2014, 50, 8797-8800. b) M. McLaughlin, R. Yazaki, T. C. Fessard and E. M. Carreira, Org. Lett., 2014, 16, 4070-4073.

20 a) E. M. Carreira and T. C. Fessard, Chem. Rev., 2014, 114, 82578322. b) G. Wuitschik, M. Rogers-Evans, A. Buckl, M. Bernasconi, M. Märki, T. Godel, H. Fischer, B. Wagner, I. Parrilla, F. Schuler, J. Schneider, A. Alker, W. B. Schweizer, K. Müller and E. M. Carreira, Angew. Chem. Int. Ed., 2008, 47, 4512-4515.

21 a) A. F. Stepan, K. Karki, W. S. McDonald, P. H. Dorff, J. K. Dutra, K. J. Dirico, A. Won, C. Subramanyam, I. V. Efremov, C. J. O’Donnell, C. E. Nolan, S. L. Becker, L. R. Pustilnik, B. Sneed, H. Sun, Y. Lu, A. E. Robshaw, D. Riddell, T. J. O'Sullivan, E. Sibley, S. Capetta, K. Atchison, A. J. Hallgren, E. Miller, A. Wood and R. S. Obach, J. Med. Chem., 2011, 54, 7772-7783. b) A. F. Stepan, G. W. Kauffman, C. E. Keefer, P. R. Verhoest and M. Edwards, J. Med. Chem., 2013, 56, 6985-6990. c) A. A. Estrada, B. K. Chan, C. BakerGlenn, A. Beresford, D. J. Burdick, M. Chambers, H. Chen, S. L. Dominguez, J. Dotson, J. Drummond, M. Flagella, R. Fuji, A. Gill, J. Halladay, S. F. Harris, T. P. Heffron, T. Kleinheinz, D. W. Lee, C. E. Le Pichon, X. Liu, J. P. Lyssikatos, A. D. Medhurst, J. G. Moffat, K. Nash, K. Scearce-Levie, Z. Sheng, D. G. Shore, S. Wong, S. Zhang, X. Zhang, H. Zhu and Z. K. Sweeney, J. Med. Chem., 2014, 57, $921-$ 936.

22 E. M. Skoda, J. R. Sacher, M. Z. Kazancioglu, J. Saha and P. Wipf, ACS Med. Chem. Lett., 2014, 5, 900-904.

23 For a recent report of 3-sulfonyloxetanes see: A.-C. M. A. Nassoy, P. Raubo and J. P. A. Harrity, Chem. Commun., 2015, 51, 5914-5916.

24 For Williamson etherification, see: a) T. Aftab, C. Carter, M. Christlieb, J. Hart and A. Nelson, J. Chem. Soc., Perkin Trans. 1, 2000, 711-722. b) S. F. Jenkinson and G. W. J. Fleet, Chimia, 2011, $\mathbf{6 5}, 71-75$. For cyclisation by epoxide opening ring closure, see: c) T. Sone, G. Lu, S. Matsunaga and M. Shibasaki, Angew. Chem. Int. Ed. 2009, 48, 1677-1680. d) E. D. Butova, A. V. Barabash, A. A. Petrova, C. M. Kleiner, P. R. Schreiner and A. A. Fokin, J. Org. Chem. 2010, 75, 6229-6235. e) K. Okuma, Y. Tanaka, S. Kaji and H. Ohta, J. Org. Chem., 1983, 48, 5133-5134. For halo-cyclisation see: f) R. D. Evans, J. W. Magee and J. H. Schauble, Synthesis, 1988, 11, $862-868$
25 For Paterno-Büchi reaction, see for example: a) M. Abe, J. Chin. Chem. Soc., 2008, 55, 479-486. b) F. Vogt, K. Jödicke, J. Schröder and T. Bach, Synthesis, 2009, 24, 4268-4273.

26 For cyclisation by intramolecular epoxide opening of glycidyl ethers, see: a) A. Mordini, S. Bindi, A. Capperucci, D. Nistri, G. Reginato and M. Valacchi, J. Org. Chem., 2001, 66, 3201-3205. b) A. Mordini, M. Valacchi, C. Nardi, S. Bindi, G. Poli and G. Reginato, $J$. Org. Chem., 1997, 62, 8557-8559.

27 P. Theobald and W. Okamura, J. Org. Chem., 1990, 55, 741-750.

28 M. E. Lebrun, P. L. Marquand and C. Berthelette, J. Org. Chem., 2006, 71, 2009-2013.

29 Assessment of the suitability of different stationary phases indicated that basic alumina activity IV was most appropriate. See: T. Boultwood, D. P. Affron, A. D. Trowbridge and J. A. Bull, J. Org. Chem., 2013, 78, 6632-6647.

30 T. E. Barder, S. D. Walker, J. R. Martinelli and S. L. Buchwald, $J$. Am. Chem. Soc., 2005, 127, 4685-4696.

$31 \mathrm{An} \mathrm{Fe}(\mathrm{OAc})_{3}$ catalysed cross-coupling with Grignard reagents was also successful with sulfonyl oxetane 1c under Fürstner's conditions to install alkyl groups. See reference 14 for further details, and: A. Fürstner and A. Leitner, Angew. Chem. Int. Ed., 2002, 41, 609-612.

32 P. A. MacFaul, L. Ruston and J. M. Wood, Med. Chem. Commun., 2011, 2, 140-142.

33 Gaussian 09, Revision C.01, M. J. Frisch, G. W. Trucks, H. B. Schlegel, G. E. Scuseria, M. A. Robb, J. R. Cheeseman, G. Scalmani, V. Barone, B. Mennucci, G. A. Petersson, H. Nakatsuji, M. Caricato, X. Li, H. P. Hratchian, A. F. Izmaylov, J. Bloino, G. Zheng, J. L. Sonnenberg, M. Hada, M. Ehara, K. Toyota, R. Fukuda, J. Hasegawa, M. Ishida, T. Nakajima, Y. Honda, O. Kitao, H. Nakai, T. Vreven, J. A. Montgomery, J. E. Peralta, F. Ogliaro, M. Bearpark, J. J. Heyd, E. Brothers, K. N. Kudin, V. N. Staroverov, R. Kobayashi, J. Normand, K. Raghavachari, A. Rendell, J. C. Burant, S. S. Iyengar, J. Tomasi, M. Cossi, N. Rega, M. J. Millam, M. Klene, J. E. Knox, J. B. Cross, V. Bakken, C. Adamo, J. Jaramillo, R. Gomperts, R. E. Stratmann, O. Yazyev, A. J. Austin, R. Cammi, C. Pomelli, J. W. Ochterski, R. L. Martin, K. Morokuma, V. G. Zakrzewski, G. A. Voth, P. Salvador, J. J. Dannenberg, S. Dapprich, A. D. Daniels, Ö. Farkas, J. B. Foresman, J. V. Ortiz, J. Cioslowski and D. J. Fox, Gaussian, Inc., Wallingford CT, 2009.

34 See supporting information for further details. 